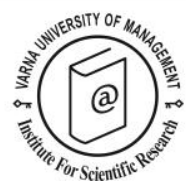

\title{
European Castles through Japanese Eyes and Minds
}

\author{
Chiemi Yagi ${ }^{1}$ and Philip L. Pearce ${ }^{2 *}$
}

Received: 06/11/2017 Accepted: 19/02/2018

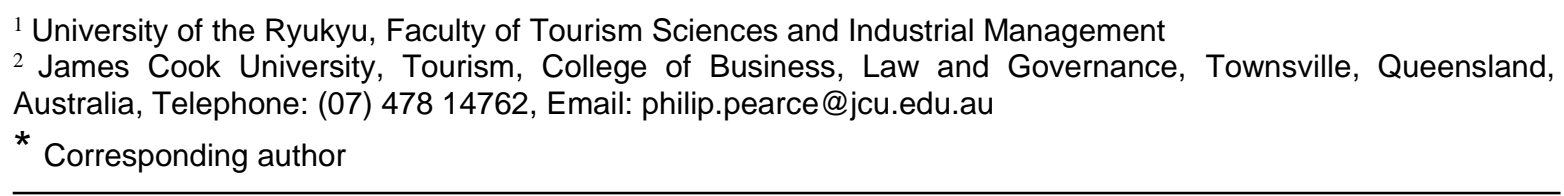

\section{Abstract}

European castles are important and common components in the tour itineraries of Japanese tourists. There is, however, limited understanding of the way Japanese tourists view these heritage sites. The first aim of the study is to document the Japanese tourists' views. Secondly, the researchers seek to explain the Japanese perspectives, while the third aim attempts to draw out the implications of the findings for our conceptual understanding of key, largely western-derived, perspectives on authenticity. Three representative European castles were selected as case study sites. Japanese remarks on TripAdvisor were collected as rich sources of data. The text-mining software Leximancer was used to analyse the broad themes. Manual content analysis was then employed for identifying the unique Japanese views. The interpretation of the Japanese perspectives was built on an understanding of the cultural capital they bring to the site - especially the legacy of anime (the Japanese entertainment format), natsukashii (nostalgia), meisho (famous places), mujou (the beauty of the transitory), and "power spots". The study identified the value of internationalising the concepts of authenticity. Practical implications for marketing European castles to the Japanese are noted.

(C) 2018 Varna University of Management. All rights reserved

Keywords: European castles, expressive reactions, Japanese culture, authenticity, place making.

Citation: Yagi, C., P. Pearce (2018) European Castles through Japanese Eyes and Minds. European Journal of Tourism Research 19, pp. 5-22

\section{Introduction}

Japanese tourists have been important contributors to European tourism businesses for some time. They were one of the first Asian tourist groups to visit Europe and remain an important market across the continent (Ahmed \& Krohn, 1993; Pearce \& Wu, 2017). France, Italy, Germany, Spain and England, among others, are particularly popular countries for outbound Japanese tourists. Conte-Helm
(2013) summarised the style and continuing importance of the Japanese: "(they) fleetingly and collectively pass through Europe, their picture postcard expectations generally realised in the assemblage of people and places that the package tours provide. Each country has its own distinctive mystique and allure...the tourists' experience tends to reinforce the fantasy image which distance and unfamiliarity have bred." (2013:49). 
It can be suggested that Europe will keep attracting Japanese tourists. In a recent TripAdvisor press release reporting the top 50 international tourist destinations for the Japanese, 28 spots were from Europe (TripAdvisor, 2016a). Among the many sites popular for the Japanese, castles are some of the prime heritage attractions which feature in many package tours as well as in independently organised itineraries (GuichardAnguis \& Moon, 2008).
Japanese castles are different from the European counterparts in their appearance as well as in their cultural meanings. Castles in Japan were predominantly built in the Edo period when Shogun was in power. They are elegantly tiered structures and played a very strong role in defending territory. For example, the World Heritage listed Himeji Castle in Hyogo prefecture and Matsue Castle are wellknown sites and it is apparent, as indicated in Figure 1, that their architectural features make them very different from European structures.
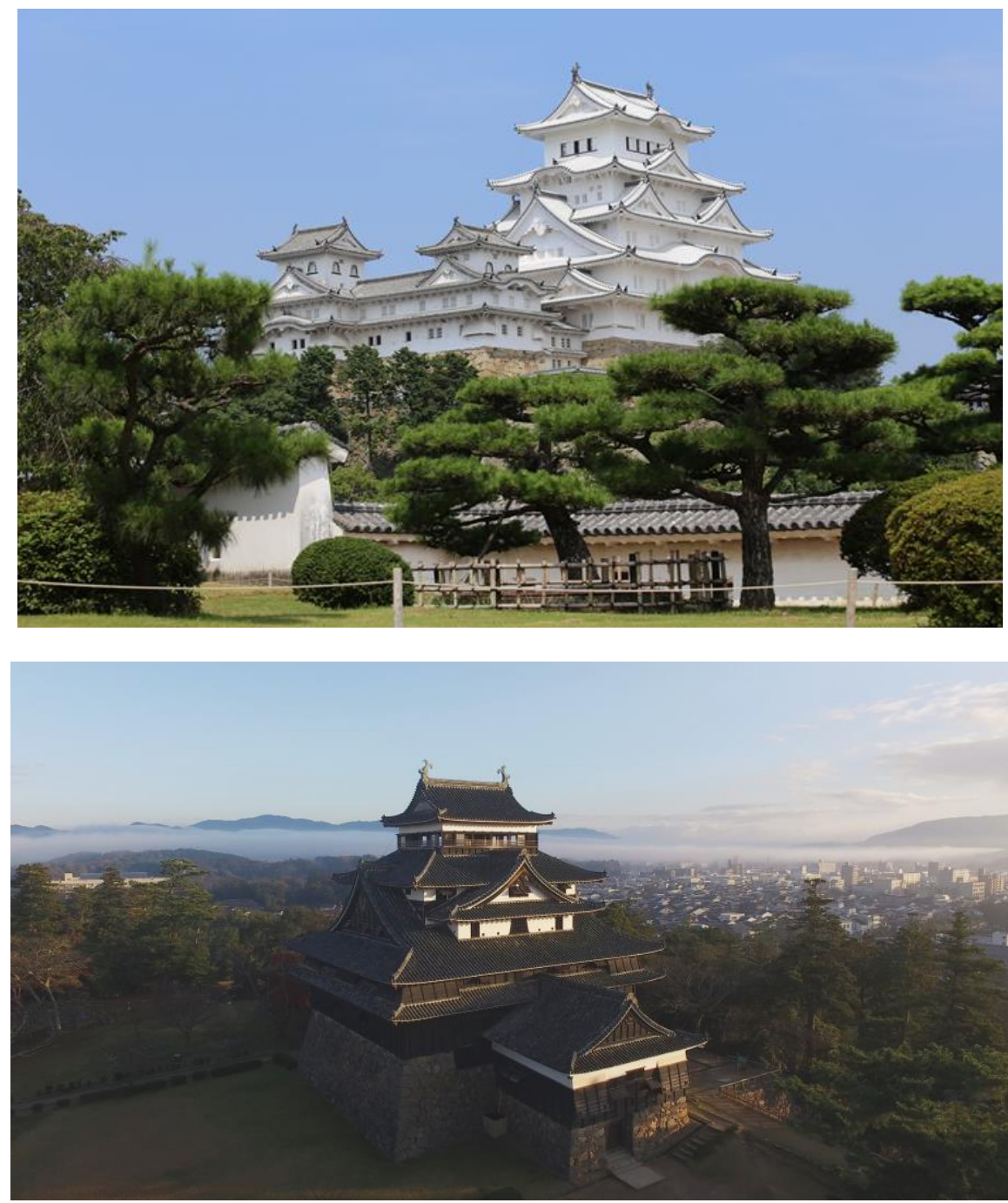

Figure 1. World Heritage Himeji Castle, Hyogo prefecture (above), and Matsue Castle, Shimane prefecture (below). (used with permission); Acknowledgements to the City of Himeji: Himeji Castle (C) City of Himeji; and the Shimane Prefecture: "Matsue Castle" ( ) Shimane Prefecture (Licensed under CC BY 4.0) 
In contemporary times, the older heritage based Japanese castles are very familiar to the public in Japan due to their extensive use as locations in historical dramas on television. By way of contrast, in the minds of the Japanese, European castles belong to distant foreign cultures and there is limited understanding of when, where, and why they were built.

Questions such as "what makes European castles special to Japanese?" and "what are the key concepts that add special charm and meanings to European castles for the Japanese?" are starting points in seeking to understand responses of these East Asian visitors to Europe. More specifically, the aims of the present study are firstly to examine the Japanese tourists' responses to select European castles and, secondly, to interpret any seemingly distinctive responses using the concepts of cultural capital and select aspect of authenticity. In keeping with the idea that contemporary studies in tourism need to go beyond descriptions of tourist-setting encounters, the third aim of the work is to comment on ways in which the study of the concepts and mental frameworks driving Japanese tourists might add to our conceptual treatment of the ideas of authenticity and place making.

\section{Literature Review}

Three sets of conceptual approaches are highly relevant to the development of the present investigation. The core areas of interest underpinning the inquiry are the differences between tourists' instrumental and expressive evaluations of attractions and facilities, the role of cultural capital in shaping the perceptions of tourists, and the contemporary views of authenticity and place making which derive from the older traditions of objective authenticity.

\section{Instrumental and expressive evaluations}

In considering the way tourists respond to attractions, a key and long standing distinction can be noted between expressive and instrumental reactions (Noe, 1999; Swan \& Combs, 1976; Ryan, 1995). Instrumental components of satisfaction refer to the physical aspects or the mechanisms that support the tourist experience. These instrumental elements, which are very often prominent in quantitative approaches to satisfaction, rely on the basic facilities and the service provided (Pearce \& Wu, 2015). By way of contrast, expressive components describe the psychological meaning that tourists attach to the more intangible and holistic features of the setting. Expressive reactions reflect the ambience of the visited location, its theming and the appeal of the storytelling. A narrow focus on measuring instrumental attributes may miss the very reasons people come to the tourist attraction, but an exclusive assessment of expressive perspectives may overlook the fundamental requirements needed for tourist attraction success (Noe, 1999). In showcasing the relevance of these concepts to the views of tourists from different cultural groups, Pearce and $\mathrm{Wu}$ (2016) demonstrated that the nationality groups from Asia and North America differed considerably in their expressive appraisal of an Australian heritage site.

It is possible to propose that cultural differences in tourists' reactions to attractions may operate for both the instrumental and the expressive domains. For example, while many tourists may have many common instrumental needs (easy parking, safe paths, and comfortable restroom facilities), some cultural differences can be envisaged (translation services, souvenir options, and different kinds of food products). There may also be common and distinctive reactions at the expressive level. As Urry (1990) argued some time ago, the views and appreciation of physical landscapes and places rests in part on cultural capital or frames of mind. Both for rugged, isolated landscapes and for buildings, those seeking a romantic gaze prefer solitary contemplation of striking spaces where the human presence is minimal. This perspective may be at odds with the collective gaze of those who wish to see other people and a sense of person-environment harmony in their field of view (Nyiri, 2006). The terms and conceptualizations which these orientations bring to viewing heritage sites may include distinctive emphases on such themes as harmony, balance, tranquility and value (Pearce, Wu \& Osmond, 2013).

\section{Cultural capital}

The term capital in this context follows the ideas originally outlined by Bourdieu and refers 
to the broad and well-established meanings which individuals acquire from their social and educational milieu (cf. Bourdieu, 1986; Carney, 2003; Putnam, 2001). A tourist arriving at a European castle can be thought of as bringing with them two kinds of cultural capital; one at the broad and common level and the other at a more personal scale. Personal capital represents a more specific individual, even idiosyncratic, awareness of the traditions and meanings of the European castles due to personal interests and tastes. There is also a broader cultural capital which Japanese tourists may bring to their appreciation of European castles. Such perceptual filters rest on several key ideas from both the traditional and contemporary culture of Japanese life (Sheridan, 1999). Six terms can be identified: akogare (admiration of the western world), natsukashii (nostalgia), the role of anime (the stylistic and artistic depiction of places), meisho (the concept of famous places), mujou (the beauty of the transitory), and "power spots" (cf. Yagi \& Pearce, 2017).

In identifying these broad cultural frames, it is potentially useful to specify the way they might operate at the individual level. It has already been suggested that individuals have their own personal histories modifying and augmenting the influence of these broad forms of cultural capital. The theory of personal constructs first devised by Kelly (1955), and subsequently used in clinical and social psychology studies (Fransella, 2003), offers a resolution as to how these two kinds of capital work together. Kelley's theory argues that individuals see the world through a set of personal constructs, where these ways of looking at people and places represent the fine-grained personal summaries of the multiple influences on experience. Kelly also recognises that individuals as social beings need to have a commonality in their construct systems and he proposes that the analysis of individual construct systems can be useful for personality and clinical analysis whereas sociability and commonality constructs are appropriate when researchers are trying to understand the behaviours and experiences of clusters of individuals (Green, 2004; Reynolds, 2013).
Building on these views, and the terms defining Japanese cultural capital, the present study will seek to explore the generic rather than the individual constructs depicting Japanese expressive and instrumental reactions to European castles. This requires the analysis of large rather than small and specialised data sets and the approach lends itself to the use of archival material recording tourists' views.

\section{Authenticity themes}

The long-standing interest in the topic of authenticity in tourism studies has several applications to the present work concerning the perception of European castles. At the simplest level, the original and foundation concept of object authenticity (cf. MacCannell, 1973, 1976; Cohen, 2007) presented the idea that it was possible to determine whether a site or attraction was authentic based on its degree of presentation to tourists. In this view those places which were modified for tourists were designated as front stage and seen as inauthentic, while the places which were not modified for the tourism presence were labelled as real, backstage and authentic. In the trajectory and evolution of this concept, the dichotomy was seen to be flawed and extensions beyond the basic model recognised emergent authenticity (modified places which were famous for being famous) and subjective authenticity (a view where the individuals' judgments determined the authenticity of the setting) (Rickly-Boyd, 2013).

Academic analyses have focused strongly on one aspect of subjective authenticity, specifically that of existential authenticity where the individual is seen as advancing their understanding of their own life and their place in the world; a revelation sometimes associated with or dependent on uplifting and numinous moments in which they engage with the setting in a rich, personal way (Cohen, 2007; Steiner \& Reisinger, 2006; Wang, 1999). For the present interest in Japanese views of European castles, it is possible to conceive of the relevance of authenticity in two ways, both of which follow the traditions outlined in the literature but which may have a distinctive twist due to the unfamiliarity of the observers. Firstly, it is potentially likely that Japanese viewing select and major European castles will relate 
their viewing experience to the extensive media and promotional portrayal of standard and wellpublicised castle images. As Rojek (1997) reported, an eclectic grabbing of past images and memories often underpins tourists' immediate evaluation of their experience as authentic. A second sense of authenticity may also be possible and relate to the tourists' desire to have a live or hot authentic experience as noted by Cohen and Cohen (2012). In this approach to contemporary authenticity interpretations, the Japanese tourists may actively co-create a memorable and authentic experience by their on-site actions and behaviours, a process which can include personalising the visit through distinctive actions, photographs and a sense of play. These ideas have been embraced in much of the contemporary work describing embodied subjective authenticity (Rickly-Boyd, 2013). Indeed, the ideas of tourists' using roleplay and the company of others to own the experience is a current of ideas flowing through much tourism literature (Baerenholdt, et al., 2004; Moore, 2002; Pearce, 1988; Prebensen, Vitterso \& Dahl, 2013; Rojek, 1997).

By integrating the ideas from this focused review of germane literature, it is possible to explore the ways Japanese tourists view select European castles in some depth. The aims of the work can be specified and refined in the light of the ideas portrayed in the literature review. The present study has three aims. As a first aim, the researchers seek to document Japanese tourists' responses to select European castles. A second aim is to interpret any seemingly distinctive responses using the concepts of cultural capital and select aspect of authenticity. The third aim of the work is to reflect on the ways in which this specific study of Japanese tourists in Europe might add to our conceptual treatment of the ideas of authenticity and how places are appreciated and consumed.

\section{Method}

The method for this study consists of the following core components and phases. Three European castles were selected as sites. The remarks posted by Japanese travellers on TripAdvisor constitute the data for the study. From these text-based data, frequently appearing concepts were revealed through Leximancer. The less frequent terms with uniquely Japanese themes were identified through additional manual coding.

\section{Selection of the Sites}

It was decided to choose famous and wellvisited castles. Castles which were ostensibly different from each other but nevertheless prominent in Japanese tourists' itineraries were chosen. Castles selected for this study were Neuschwanstein Castle (Germany), Mont St. Michel (France), and Windsor Castle (UK). Neuschwanstein Castle is the most visited castle in Germany with more than 1.3 million visitors yearly (Neuschwanstein Homepage). Neuschwanstein Castle is listed as the first castle in TripAdvisor's "bucket list for world castles", and is often cited as a destination to visit when the Japanese travel in Europe (TripAdvisor, 2016b). Mont St. Michel is also well known and is listed as a World Heritage Site. As a famous place of pilgrimage, Mont St. Michel attracts around three million visitors annually. In 2009, a city friendship agreement was signed by Mont St. Michel and Miyajima, Japan, drawing similarities between the two places as seaside sites of religious significance with more than 1000 years of history. The tourism promotion photos with Mont St Michel and Miyajima next to each other, both floating on the ocean, have attracted considerable attention in Japan. Windsor castle has a close association with the royal family and is still used as a working castle. Although Windsor castle is arguably not as central to visiting Britain as Buckingham Palace, nevertheless tourists are permitted to enter the site, thus making it suitable for comparisons and commentary as a more involving tourism experience. In combination, the castles selected were all popular and covered the themes of romance, religion and royalty. The multi-national research team visited the three sites in the study which assisted with understanding the names of the castle features and facilities, and helped at times with the interpretation of the tourists' experience.

\section{Data collection}

Data were collected from TripAdvisor's web site in June 2016. The name of each castle was used as a keyword in the TripAdvisor's website 
Table 1. Number of comments in TripAdvisor for each castle.

\begin{tabular}{cccr}
\hline Castle & $\begin{array}{c}\text { \# total comments } \\
\text { in all languages }\end{array}$ & $\begin{array}{c}\text { \# comments in } \\
\text { Japanese }\end{array}$ & comment listed period \\
\hline Neuschwanstein Castle & 10,253 & 414 & $2008.9 .1-2016.6 .21$ \\
Mont St Michel & 7,437 & 874 & $2008.9 .5-2016.4 .15$ \\
Windsor Castle & 6,545 & 94 & $2008.12 .14-2016.611$ \\
\hline
\end{tabular}

(tripadvisor.jp) top page. The search led to the site for reviews from TripAdvisor's Community for each selected castle. For the Mont St Michel case, it was noticed that there were additional phrases used for the location ("Abbaye du Mont-Saint-Michel" and "Fortification du Mont-Saint-Michel"), thus both were included and considered as one set of data for Mont St Michel. Only those reviews which were written in Japanese were included as data for this study. The data for the study are reported in Table 1.

\section{Data analysis procedure}

The data were analysed using a text mining software Leximancer (LexiPortal Version 4) and also by manual coding.

\section{Analysis by Leximancer}

Leximancer is a powerful tool for analyzing text data (Wu, Wall and Pearce, 2014). Since Leximancer was not designed for the Japanese language, it was necessary to modify the online data for this software. More specifically, Leximancer is based on morpheme analysis with the implication that the language should have clear markers for word and sentence breaks. Further, a complete 'stop-list' of frequently used terms (for example 'and', 'the', and 'but'.) must be compiled in the desired language, so that these words can be excluded from processing as concept candidates (Leximancer website, 2016). There is no space between words in a sentence in the Japanese writing system (unsegmented), thus the very first task was to transform the data into the spaced-wording format. For this study, online free software "TinySegmenter (http://chasen.org/ taku/software/TinySegment er/)" was used to undertake this task. Running TinySegmenter alone was not sufficient preparation for Leximancer, and it required some manual adaptation and editing to make sure every space was correctly located at the right spot for the correct meanings. After several trial and error steps, the data were successfully prepared and made "Leximancerready".

Following the running of the software, translation into English of the concepts was necessary to make the presentation accessible to a non-Japanese audience. That was done by replacing all the Japanese words in the concept word list into English equivalents. The process could have been conducted in reverse; that is translating all the Japanese data text into English before running Leximancer. That approach, however, would be enormously time consuming when working with a large numbers of responses. The three data sets for each castle were separately treated and processed by Leximancer.

\section{Manual Content Analysis}

Some terms of interest in this study appeared less frequently, and thus were poorly represented in the Leximancer output. That is, for large data sets the algorithms in Leximancer provide a solid overview of the very frequently occurring terms and these expressions tend to dominate the visual output from the program. It was necessary, therefore, to use manual coding to assess the lower tier of phrases and expressions used by the Japanese tourists. All the comments in the data were carefully read three times, with a two week interval on each occasion, and notes were taken each time to capture the comments, phrases and words pertaining to Japanese social and cultural perspectives.

\section{Results}

This section reports the core visual results from the Leximancer analysis for each castle. The 
information identified through the manual coding approach completes the presentation of the material in this Results section. The balance between instrumental and expressive remarks and those which might be thought of as more distinctive due to cultural capital and a concern with authenticity are considered in the Discussion.

\section{A) Results from Leximancer}

\section{Neuschwanstein Castle}

Fifty-two concepts, including three name-like and 45 word-like concepts, were identified by the Leximancer program. Figure 2 depicts the themes and concepts in the remarks for Neuschwanstein Castle created with Leximancer. "Castle", "time", "bus", "beautiful", "language", "ban", and "path" were identified as the six most dominant themes representing Japanese experiences visiting Neuschwanstein Castle.
"Castle" is the base theme in the remarks of the Japanese who visited Neuschwanstein Castle. This word was mentioned 1,331 times in 414 reviews. It includes the general description of the destination - the "castle" called "Neuschwanstein Castle" in "Germany" was a "good" place for "sightseeing" and "external appearance" was "splendid" especially the "view" from "Marien Bridge" for "photographing". Many reviews expressed their long-held desire for visiting the castle and/or identified the castle as the essential attraction in their visit to Germany. "This castle is the absolutely must to visit in Germany" and "The castle represents Germany! It is a splendid castle built in the middle of the mountain. Photography is good from Marian Bridge."

"Time" emerged as an important theme for visiting Neuschwanstein Castle. Often, it was linked to the "time" "spent" in a "long" "queue"

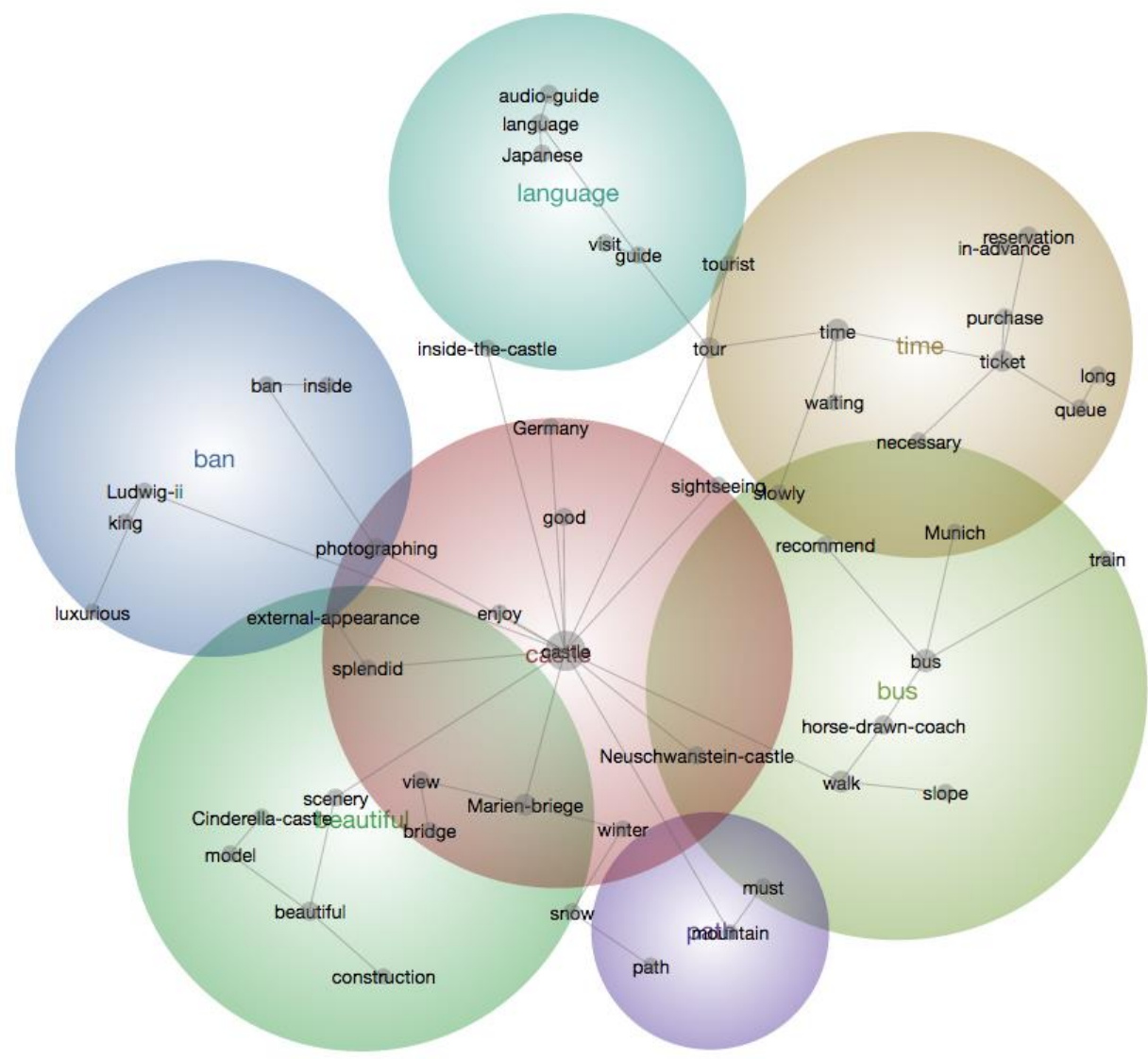

Figure 2. The themes and concepts in the Japanese remarks for Neuschwanstein Castle 
for "waiting" to "purchase" a "ticket" to enter the castle, or recommending others to "purchase" a "ticket" "in advance" with "a reservation" in order not to waste "time" in "long" "queue". Many Japanese indicated that they were annoyed by the time spent waiting in the line because there are many visitors and queues move very slowly.

"Bus" is the third largest theme. It represents the transportation mode both for long distance from "Munich" (alternative mode is "train") and for relatively short trip from the bottom of the hill, from where visitors have choices of "bus", "walk" or "horse-drawn coach" to get to Neuschwanstein Castle. Taking bus was often "recommend"-ed for the latter because of the long "slope".

"Beautiful" was picked up 210 times in the total of the 414 reviews. It is used to describe the "external appearance" of Neuschwanstein Castle, often from the "view" from "Marien Bridge", and the whole "scenery" sounding the castle. "Cinderella Castle" was frequently mentioned as a beautiful "model" castle of Neuschwanstein Castle as one commented "Just like the photograph in the guidebook, the castle from Marien Bridge was beautiful to a superlative degree as I had expected. As might be expected as the model of Cinderella Castle in Disneyland, it was the most beautiful castle I have ever seen."

"Language" was counted 144 times. In most case, it is related to Japanese language either the visitor joined the Japanese speaking tour "guide", used (or recommend to use) "audioguide" in Japanese language, or heard Japanese language at the site because there are many Japanese visitors there. Many expressed their appreciation for the Japanesespeaking tour guide. Additionally, the availability of Japanese language audio-guides that made their visit easier and boosted their understanding of the history of the castle. On the other hand, hearing Japanese language from other visitors made them rather uncomfortable because it created the atmosphere of as if "being in Japan".

"Path", was counted 45 times, and this theme related to the path to the "castle" and the "mountain" view through the path, which was sometimes covered with "snow". "Ban" was counted 64 times and is strongly related to "photographing" and "inside" of the castle. Overall, many remarks expressed regret and sometimes annoyance that photographing is not permitted to capture the luxurious interior of King Ludwig II's castle. Some even wrote, "I think the interior of the castle was splendid, but I am afraid I don't remember anything at all because photography was not permitted inside of the castle." These remarks somewhat explain the scantiness of the descriptions about the inside of the castle compared to the abundant appreciative remarks about the castle's external appearance and surrounding scenery.

\section{Mont St Michel}

Sixty-two concepts, including 5 name-like and 57 word-like concepts, were identified by the Leximancer program. Figure 3 provides the themes and concepts in remarks for Mont St Michel created with Leximancer. "Mont St Michel", "night", "monastery", "scenery", "souvenir", "France", "omelet" and "park" were identified as the seven dominant themes representing Japanese experiences visiting Mont St Michel.

"Mont St Michel" is the strongest theme. It was recorded 730 times in 864 reviews of the Japanese who visited Mont St Michel. It is the title (name) of the destination attraction and is predictably important. In the Leximancer map, the name is connected to the special status of "World Heritage", close to "Paris" and a place for "sight-seeing". Further, the modes of transportation such as "TGV (Train a Grande Vitesse, the bullet train in France)" and "bus" for "one-day trip" and "tour", are linked to the theme and described positively with such adjectives as "fantastic" and "beautiful".

"France" is the second strongest theme with 124 counts. Typical expressions with this theme include "It is definitely Mont St Michel when it comes to France even though it is quite a distance to travel." "very famous World Heritage in France", "This place is the most impressive one in my trip to France." and "a very impressive sight-seeing spot in France". 


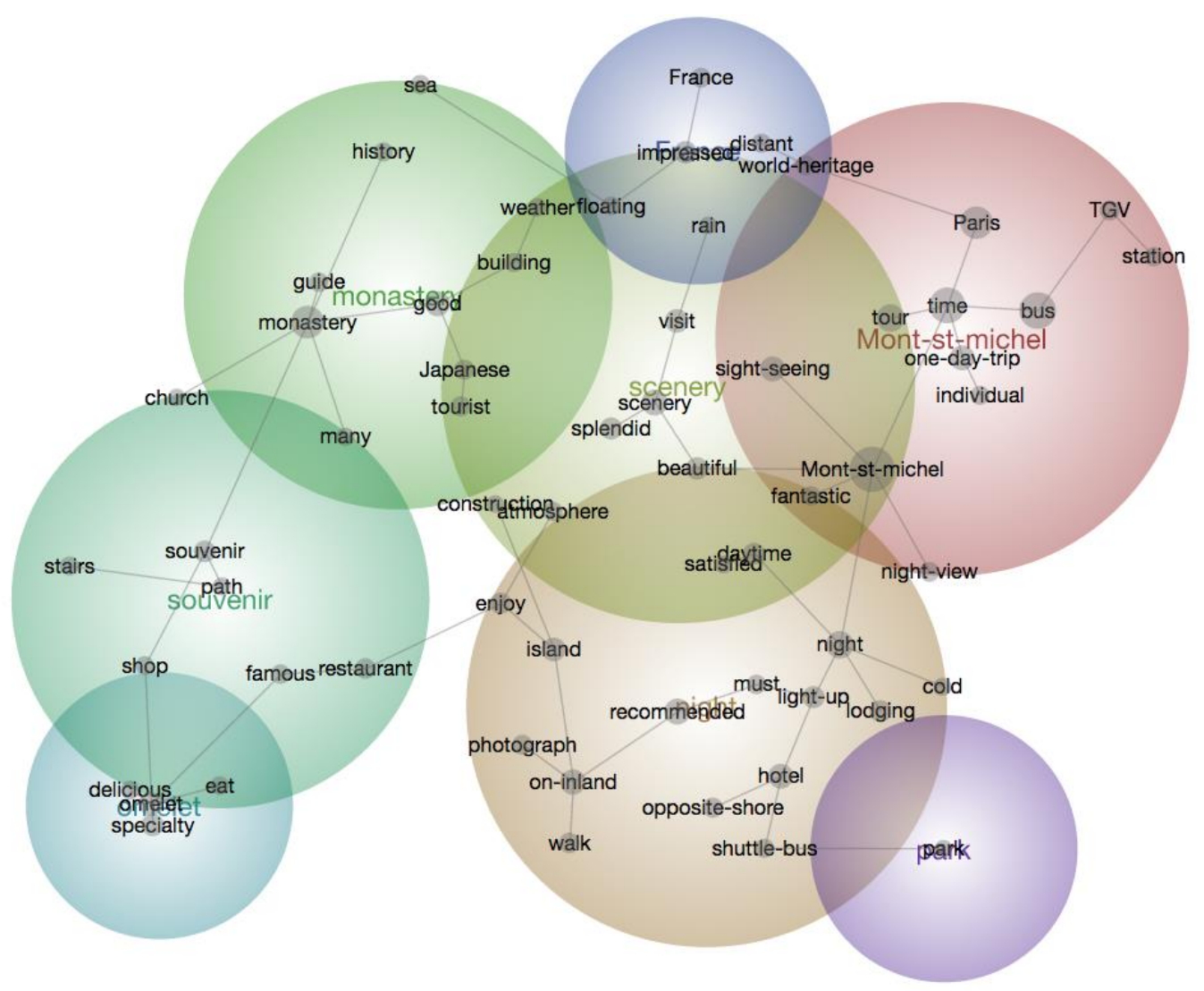

Figure 3. The themes and concepts in remarks for Mont St Michel

"Night" is another strong theme. While people visiting Mont St Michel during "daytime" were quite "satisfied", "night" visit was "recommendded" by many as a "must" because the place becomes mysteriously beautiful when "lit-up" and when there are fewer people around. It was noted that it is "cold" at night and tourists need "lodging" but a "shuttle bus" is available from the "hotel" on the shore. "Walking" and taking "photographs" on the island was "enjoyed" at night. Those who only had a day trip expressed their regret that they could not stay to view Mont St Michel at night, and some even promised themselves to visit there again to have the night experience.

The theme "Monastery" was picked up 452 times. This study considers Mont St Michel as a castle in a broader sense, but it indeed is a monastery as many Japanese reviewers recognised. They recorded that the "building" was "floating" in the "sea" with a complicated "history" that the "guide" explained. Many evaluated their visiting experience as good, though the presence of too many Japanese tourists there was viewed as quite disturbing.

"Scenery" was considered as a theme with 227 counts. Scenery including Mont St Michel was expressed as "beautiful", "splendid" and "fantastic".

"Souvenir" was another theme and was counted 165 times. On the "path" toward the monastery" it was noted there were many "souvenir" shops. Some complained about the high price of souvenir items at these shops and the crowdedness of the area. By way of contrast, for those who visited Mont St Michel during the off-season (winter), the closure of the shops at that time of the year was disappointing. Overall, however, the Japanese seem to have enjoyed the attractive souvenir selections and shopping experiences. 


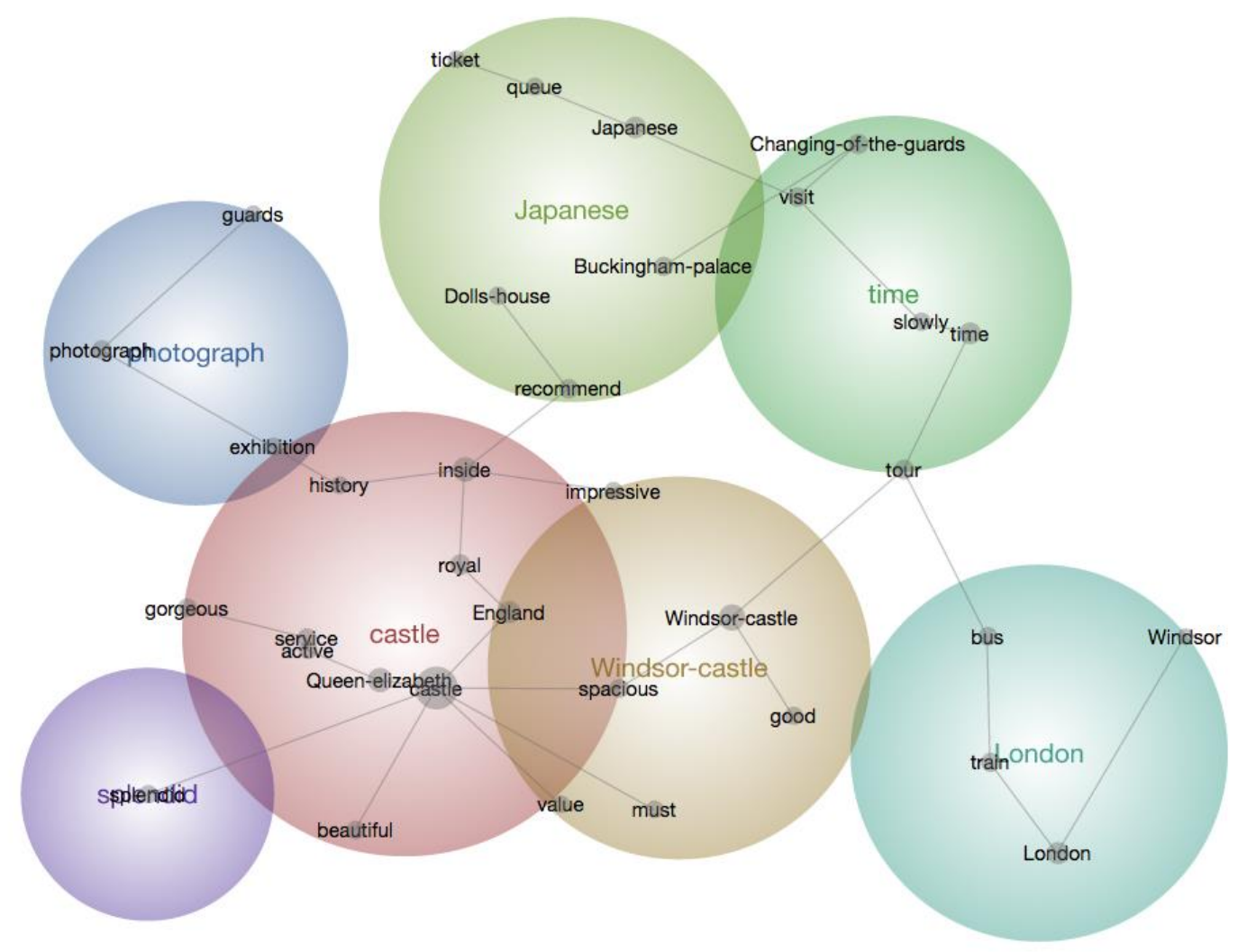

Figure 4. The themes and concepts in remarks for Windsor Castle

"Omelet" refers to the famous omelet by la Mere Poulard and counted 189 times. It is a "specialty food" on Mont St Michel and "eating" it appeared to be one of the popular touristic activities there. While "delicious" was listed as a concept, it is quite controversial because about half of the remarks that include "omelet" and "delicious" expressed their dissatisfaction toward the omelet as in such remark: "the specialty omelet - I don't recommend. I don't think it was delicious and it was too expensive. It was just airy and had no taste at all." "Park" was another theme with 71 counts. It refers to both "parking" the car and "parking" area.

\section{Windsor Castle}

Thirty-five concepts, including 9 name-like and 26 word-like concepts, were identified by the Leximancer program. In Figure 4 the themes and concepts in remarks for Windsor Castle created with Leximancer are portrayed. "Castles", "time", "Japanese", "Windsor Castle",
"London", "photograph", and "splendid" were identified as the six most dominant themes representing Japanese experiences visiting Windsor Castle.

"Castle" is the strongest theme for Japanese visiting Windsor Castle and was counted 1215 times. The visitor correctly recognised Windsor Castle as "active", meaning an "(in) service", "royal" "castle" in "England" with strong connections to "Queen Elizabeth", the current Queen, as she visits and stays there some weekends. It is described as a "beautiful" or "gorgeous" castle with "impressive" "exhibitions" "inside" that shows the "history" of "royal" family and "England".

"Time" is the second strongest theme and appeared in a couple of ways. "Tour" inside the castle takes quite a "time" if tourists move "slowly" to "visit" each buildings and each room. Also the "time" for "Changing of the guards" 
was mentioned by some as a ceremonial ritual not to be missed.

"Japanese" is another strong theme. Unlike the other two castles, the number of Japanese visitors to Windsor Castle was relatively small, so remarks tend to mention that other "Japanese" were not seen in the "queue" for the "ticket" purchase. At the same time, many mentioned the free "Japanese" language audio guide that they can listen to for the explanation of the castle's features, and expressed the appreciation as in these remarks, "Japanese language audio-guide was easy to listen to and good. I recommend to use it", and "You can borrow the Japanese language audio-guide free of charge. It explains the roles of the rooms and pictures, ....all the highlights of the Castle."

"Windsor Castle" is listed as a theme with 52 counts. It is natural to have the title of the destination as a theme. It reflects that Windsor Castle was considered "spacious" and has "value" for a "must" visit because those who made the trip found the visiting experience "good". The theme "London" was counted 45 times. "Windsor" is located in greater London's west and to get to "Windsor" from central "London", the common transportation forms were "train" and "bus".

"Photograph" is another key theme for Japanese visitors to Windsor Castle. Most of the "exhibitions" do not permit photography, but tourists still enjoyed taking photographs of the castle's outward appearance and the "guards"both those on duty for security and at the changing-of-the-guards ceremony. Also "splendid" as a theme was counted 21 times, and was used to describe the castle's interior and its garden, and as a characterization of the overall visit.

\section{B) The manual coding}

In tourists' reports of their visits to many attractions, instrumental or pragmatic issues occupy considerable space (Noe, 1999). The Leximancer results confirm this point with a substantial number of the most common expressions including remarks about transport, the logistics of visiting, language facilities, and shopping. Distinctive Japanese views, as potentially noted in the literature review, were also found in the tourists' remarks but were not readily apparent in the top tier phrases depicted in the Leximancer maps. The manual coding initially detected the presence of remarks comparing Japanese castles and the European castles. For Neuschwanstein Castle, two actual locations in Japan were mentioned. The first was Himeji Castle, a World Heritage listed castle in Himeji city, Hyogo Prefecture. It is also called White Egret after its appearance resembling a flying white egret. Parallels between the beauty of Neuschwanstein as a Japanese Himeji Castle were drawn and the formal Tourism Exchange Agreement between two castles which was concluded in 2015 was occasionally noted. Another comparison was made with Cinderella's castle in Tokyo Disneyland (There seems to be a common belief that Neuschwanstein Castle is the model of Cinderella Castle in Tokyo Disneyland, while it actually has several European castles combined as a model.) Its fairytale-looking structure is often recognized and connected with castles in Disneyland. One remarked "The genuine one is indeed fantastic!" referring to the Neuschwanstein Castle as authentic and original compared to Cinderella Castle in Disneyland.

Two other items that were relatively frequently observed in the set of remarks from Japanese visiting Neuschwanstein Castle referred to the reproductions and communication of the images of the German castle. For some, Neuschwanstein appeared in the fairytale or picture books they had heard or read as small children. The terms puzzles and calendar were also used as in "This castle is a famous one as the calendars and puzzles were sold in Japan" and "I made a jigsaw puzzle of the castle when I was young". Those remarks provide some information revealing how some Japanese had built a familiarity with Neuschwanstein Castle since childhood.

For Mont St Michel, two locations in Japan were mentioned as bearing a strong resemblance. One is Enoshima, one of the popular travel destinations in Shounan, Kanazawa Prefecture, famous for its picturesque scenery. This island, while it is connected with a bridge, floats in the ocean at 
high tide. Tourists mentioned the resemblance of this imagery. Another link was sometimes made to Kiyomizu Temple, one of the most famous temples in Kyoto. It is, however, not the temple itself but the approach to the temple that the remarks emphasized.

Some links to Japanese pop-culture were noted. The most frequently mentioned was "LAPUTA: Castle in the Sky" (anime by Hayao Miyazaki and studio Ghibli). The appearance of Mont St Michel as if floating in the ocean resembles Laputa which floats in the sky. A second link was made to The Castle of Cagliostro (Japanese manga by Monkey Punch and its anime movie by Hayao Miyazaki released in 1979, which was again put on the screen in 2014 with a digitally remastered version). The castle in the fictional country, Cagliostro, is floating on the ocean and, depending on the tide, is connected to or separated from the land, just like Mont St Michel. These environmental links and connections support the rumors that Mont St Michel is the model of Laputa and the Castle of Cagliostro. There were occasional but not unimportant remarks to other television and film scenes and settings in Japanese entertainment which used Mont St Michel in special episodes or scenes.

For Windsor Castle, one actual location in Japan was mentioned in the remarks - that was the Japanese Imperial Palace, Tokyo, where the Japanese emperor lives. It is not so much the appearance but the royal connection which generates the remarks. While visiting royal buildings in foreign countries, Japanese tourists compare the international examples and their domestic sites. Tourists noted that at Windsor Castle the entrance fees collected from the visitors are used for off-setting the cost of running the palace, while the expenses for the Japanese Imperial Palace are covered by taxation. Another finding from manual coding of the Windsor Castle reviews was that some Japanese associated Windsor Castle with the books and films about Harry Potter, based on J.K. Rowling's series of novels. Atmosphere and Englishness appeared to be the basis of the link.

\section{Discussion}

For the aims of this study, the results reported in the Leximancer analysis, and expanded upon in the findings from the manual coding, serve to catalogue in detail the Japanese tourists' responses to select European castles. In the eyes of the Japanese, European castles do appear as beautiful structures, a perspective undoubtedly shared by many international tourists. Japanese tourists use many adjectives such as beautiful, elegant, and magnificent to describe and praise the castles' attractive styles. From the analysis of the Japanese remarks, however, it became apparent that there are some points that are special for the Japanese when appreciating the European castles. These perspectives are tied to Japanese culture. A discussion of these points, as follows, addresses the second aim of the study.

\section{Japanese appreciation for beauty and unseen power}

The quiet appreciation of refined beauty and power is captured in part by the Japanese term wabi sabi (quiet aesthetic appreciation). It is beyond the scope of this paper to fully explain the concept of wabi sabi because of its complex and deeply-rooted value with Buddhism. For more explanation, see Koren (2008). Mont Saint-Michel at sunset, for example, was often profoundly appreciated more because of its imposing, yet simple and even somber outline connoting solitude, rather than its obvious external outline. Japanese find beauty in simple and somber scenes, especially if there is a sense of time and history embedded in the view. Related to this value of wabi sabi, mujou is another Japanese expression which assists the interpretation of places. Simply put, mujou means that all worldly things are transitory. Japanese have an almost synesthetic appreciation of evanescence (Kodansha, 2003): an acute awareness that youth, beauty and prosperity will not last forever. The philosophy of mujou underpins the appreciation of Neuschwanstein as well as Mont Saint-Michel. While viewing the dreamingly beautiful Neuschwanstein, Japanese tourists consider the transitions in the life of Ludwig II from luxurious indulgence in his wealth to the accusations of insanity and his early death. This notion of ephemeral success 
fits closely with the mujou concept. When viewing the magnificent Mont Saint-Michel, Japanese tourists tend to reflect on all that has passed in this location over time, employing their distinctive philosophy of mujou to view the world. Multiple comments in the content analysis reiterated the theme of the passing of the centuries and the passage of time. Similarly, though at a briefer time scale, Japanese visitors who stay in the region may observe Mont Saint-Michel at different times of the day and feel that they too are a part of ever-changing being. Sites which generate the feeling of mujou are regarded as memorable and beautiful, and certainly somewhere to be much appreciated.

\section{Meisho - Noted places}

The Japanese craze for photo-taking was highlighted in the Leximancer remarks at Neuschwanstein and Mont Saint-Michel. This enthusiasm is driven partly because they want to capture the image of the castle itself, and partly because they want to replicate the way the castles are portrayed in the media such as travel guidebooks. Key sites are known as meisho, noted places, which one must visit (Moore, 1985). Japanese travel guidebooks are more richly illustrated with quality photographicimages compared to the English-language travel guidebooks, which are far more textbased. Nishimura, Waryszak and King (2006) comment that for the Japanese the "Travel guidebook has a function of a travel motivator as well as an image expander" (p.18). That is why Japanese comments reveal their devotion to taking photos of Neuschwanstein from the viewpoint of the bridge. Tourists are at the destination to confirm that the real architecture fits what they have seen in the travel guidebooks. This is a distinctively visual, hot authentication of object authenticity (Cohen \& Cohen, 2012). The Japanese take photos to provide evidence of being there and as "kinen", legitimizing mementos (Moore, 1985).

In addition, the Japanese fascination with the picturesque settings of Neuschwanstein and Mont Saint-Michel lies in the appreciation of the harmony of nature and human beings; the smooth conjunction of the built and the natural. Both Neuschwanstein in deep green woods, or in snow, and Mont Saint-Michel floating in the ocean, look harmonious in their natural surroundings. Japanese visitors find such unity to be prime examples of beauty. These same ideas of harmony underlie the Japanese garden and Neuschwanstein and Mont SaintMichel are large scale versions of the theme.

The Japanese comments also embody the operation of the concept of a "power-spot". The expression power-spot is Japanese English, an English word coined in Japan that means a location, which is thought to be flowing with mystical energy. It is said in Japan that one can receive good fortune and healing at the powerspot. Visiting such places is becoming increasingly popular for the Japanese (Kato \& Progano, 2017). In Japanese life, nature is not just important but is thought to provide spiritual and bodily purification (Krag \& Prebensen, 2016). Power-spots are usually religious places, old ruins or impressive and spectacular natural places. Tourists reported that they had been told that Mont Saint-Michel was a powerspot. Even for those who did not use the word power-spot, many mentioned that they felt their heart was washed or purified by visiting this French castle. It was noted that none of the Japanese who wrote the remarks visited Mont Saint-Michel for a truly religious pilgrimage purpose as a Christian; however, some did make a pilgrimage for this power-spot. As Watkins and Gnoth (2011, 1278-1279) explained, it may be the part of the Shinto faith to find the sacred power in nature and places for Japanese.

\section{Akogare - admiration for Western culture, and natsukashii (nostalgia)}

English and European Castles are omnipresent in Japanese children's picture books and fairy tales. Surman, (2009) suggests that "exposure to songs, television programs, films and literature as children often reflects our personal tastes later in life." (2009:195). Fairy tales in particular seem to have influenced Japanese girls to dream of visiting European castles. Such sites serve as symbols of the Western world and previous studies have highlighted the ways in which the Japanese have admiration for western traditions and people - a concept known as akogare (Yagi \& Pearce, 2017). It was often observed that female Japanese visitors claimed that the visit to the castle was 
their dream from childhood; several directly identified the castle they were visiting as "my akogare." It can be suggested that it is not just the structure of the castle itself they had dreamed of visiting, but also the symbolic sense of visiting the shining, beautiful, happy Utopia of the Western world that they had admired. These views especially for Neuschwanstein were linked to the Disney stories of princes and princesses.

As a form of pop-culture, images from anime, manga, movies, and games were noted repeatedly in the manual coding. Japanese remarks examined in this study included particular titles of anime, such as "Laputa; Castle in the Sky" and "The Castle of Cagliostro" because of the resemblance of the castles in these anime to Mont Saint-Michel. A manga title "Nodame Cantabile" was mentioned multiple times as the trigger for the visit to Mont Saint-Michel because one of the episodes in the manga took place there. The film Harry Potter was also mentioned as the atmosphere created in the movies resonated with the impressions felt at Mont Saint-Michel and Windsor castle. Additionally, the game Dragon Quest was highlighted because the dungeon in the game parallels the one in Mont Saint-Michel. As Iwashita put it "popular cultural forms of the media can promote, confirm and reinforce particular images, views, and identities of destinations in a very powerful manner." (Iwashita, 2006, p.59). There is a term "contents tourism" in Japan, referring to all the aspects of pop culture, such as movies, dramas, anime and manga, in relation to tourism (Beeton, Yamamura and Seaton, 2013). The term is used as a part of the official language of the Japanese government in promoting inbound tourism (Seaton and Yamamura, 2015). Studies on such areas are mainly on the Japanese domestic tourism and overseas visitors to Japan, however, the present study can be viewed as an example of Japanese "contents tourism" abroad, especially when Japanese popular culture influences the reactions to the international sites.

The popular culture links reinforce two more generic issue operating in the minds of the Japanese tourists: the term furusato (homeland) overseas and the special role of natsukashii (nostalgia). Most tourists use facets of their own culture as a benchmark for their international experiences. This cognitive process is apparent in Japanese tourists remarks upon the visit to European castles. Moeran noted "Those Japanese who first went abroad as tourists did so as sightseers who wanted not just to experience foreign cultures, but to compare them with their own.... Partly to see the monuments themselves and partly to see how they compared with such Japanese monuments ..." (Moeran, 1983, p 99). Such notion of Japanese identifying the place abroad with one at home was labelled "furusato (homeland) overseas" by Rea (2000). Surman (2009) extended the term by linking it with a sense of childhood nostalgia for one's own past. European castles belong to foreign culture and yet, they are quite familiar to the Japanese, not just because of the solid information available, but also because Japanese know about European castles from their imaginary worlds; memories of those times make them feel nostalgic when visiting (McCain \& Ray, 2003).

\section{Fame and famous.}

There are certain keywords such as "world heritage", "famous", "must-see" site, and "mustdo" which appeared in the Japanese remarks. Japanese are readily influenced by titles such as "world heritage" and attractions described as meisho a "famous place". Mont Saint-Michel was frequently referred to as world heritage listed by many Japanese. It seems that they are very conscious about the idea of a place being worth visiting, and the title world heritage plays the very role of authorising as "must-go site". In the work of Cohen and Cohen (2012), this endorsement is referred to as cold authentication. As Nishimura, Waryszak, and King (2006) argued, building on the work of Siegenthaler (2002) and Graburn (1995), that Japanese tourists appear to have a special need to authenticate the existence of, and experience the famous places featured in guidebooks. In a somewhat more active way, the behaviours at the omelet restaurant at Mont Saint-Michel is a notable example of hot authentication. The food at the restaurant was mentioned by many Japanese because it was introduced by the media as a famous place and the omelet there is "something one should try". 
While many were disappointed with the taste of the omelet, one phrase was repeatedly used, "it was good kinen (commemoration)". Even when the experience itself was not satisfactory, hot authentication can build a worthwhile memory because the tourists had actively and personally fulfilled their intention to visit and engage with the site.

\section{Reflecting on authenticity.}

This section addresses the third aim of the study. Taken together, it is possible to see that these distinctive Japanese mind sets, that is the tourists' cultural capital, add to our understanding of the term authenticity. In contemporary tourism studies there has been a tendency to focus on existential authenticity, the numinous moments of special appeal which can have a lasting and at times transformative power in the tourists' life (Rickly-Boyd, 2013; Wang, 1999). The Japanese data collected in this study suggest some other ways to advance our understanding of authenticity by attending more to what has been called emergent authenticity (Cohen, 2007). This concept captures the view that some sites are famous for being famous; that is because they are promoted so much as tourist attractions that, even though some of the myths and background surrounding their story may not be fully validated, they are obligatory sites for tourists to visit. In Japan, there has been a distant international emergent authenticity operating through myth making and the media, all of which have effectively promoted some western tourist attractions. These forces have built an agenda for the must visit attractions. This construction of the desirable symbolic western world, underpinned by the broad concept of akogare, and linked to the power of childhood memories (natsukashii), drives the emotional appreciation of on-site visits. That appreciation may be in terms of the spiritual power of healing places (power spots) or in the form of a deep, almost somber, appreciation of tranquility in the transitory world (mujou). It is apparent that these concerns for the authenticity of the tourist experience in the Japanese context are less about what is real or genuine or fake, but more about the power of the setting to evoke special authenticating emotional feelings through respect, recollection and beauty. The notion that authenticity is centrally about the emotional impact of a setting is an addition and revision to the western-inspired view of the term.

\section{Conclusion}

In the expanding agenda for tourism study the appreciation of international tourists is beginning to reach beyond simple counts of how many people come to a destination and how much they spend (Pearce \& Wu, 2017). Instead, or at least in addition, researchers are beginning to tackle the meaning of the travel for tourists from other cultures and to interpret and understand the sense they make of the sites visited through distinctive cultural values (Saipradist \& Staiff, 2008).

The present study drew attention to the values of Japanese culture in shaping reactions to three important European castles. There are limitations to selecting a small number of castles and relying on written comments to form the interpretations. Supplementary work to verify the arguments and cultural values identified here would benefit the solidity of the findings. The extension of this kind of work is feasible for other categories of tourist attractions and in other continents.

For destination marketers it is important to find out what the specific destination or attraction means to the particular group of visitors; there might be some unknown appeal or charm which they can augment by their attention to opening times, interpretation and facility provision, and access to photography and commemorative activities. Evidence was provided in the Leximancer analysis that some Japanese tourists were disappointed by the restrictions on photography and some opening times; the possibility of considering how these issues might be managed to suit Japanese tourists' needs is a non-trivial recommendation from the work. There are, though, puzzles in meshing the needs of multi-cultural and multinational groups at these kinds of iconic sites. A major challenge for the research community looms in terms of identifying ways to advise management to meet multiple needs simultaneously. Certainly, tourism scholars can add new studies of this type to supplement the working knowledge of those who are required to manage such iconic attractions for mutually 
successful outcomes. It is also apparent, however, that the needs and mindsets of growing numbers of diverse international tourists require refreshing some of the tourism concepts that researchers employ. It appears that authenticity for the Japanese may be more about the ability of the tourists' imaginative capacity to generate key emotions and values, and less about the search for truth, accuracy, and credibility.

This result suggests a key direction for the future promotional efforts to inspire Japanese tourists to come to European sites. In planning for the promotion and presentation of European attractions, it can be firmly suggested that building a listing of power spots might be a fruitful exercise. In the identification of these special places, the Japanese tourists need to be informed about their emotional and spiritual properties, their history and longevity as sites of appeal, and their capacity to inspire past and current generations. All importantly, this approach introduces the opportunity for destination managers of lesser known European sites to use the many forms of contemporary communication to build new power spots where the concepts of akogare, mujou and meisho can work together to both excite the admiration and disperse the new waves of Japanese tourists.

\section{References}

Ahmed, Z. U., \& Krohn, F. B. (1993) Understanding the unique consumer behaviour of Japanese tourists. Journal of Travel \& Tourism Marketing 1(3), 73-86

Beeton, S., Yamamura, T., \& Seaton, P. (2013). The mediatisation of culture: Japanese contents tourism and pop culture. In Lester, J. A., \& Scarles, C. (eds.). Mediating the tourist experience: from brochures to virtual encounters. Surrey, Ashgate Publishing Limited, 139154.

Baerenholdt, J., Haldrup, M., Larsen, J., \& Urry, J. (2004) Performing tourist places. Aldershot, Hants; Ashgate.

Bourdieu, P. (1986) Distinction: A social critique of the judgement of taste. London: Routledge.

Carney, D. (2003) Sustainable livelihoods approaches: progress and possibilities for change. London: Department for International Development.

Cohen, E. (2007) Authenticity in Tourism studies; après la lutte. Tourism Recreation Research 32 (2), 75-82

Cohen, E., \& Cohen, S. (2012) Authentication: Hot and Cool. Annals of Tourism Research 39(3), 1295-1314

Conte-Helm, M. (2013) The Japanese and Europe: economic and cultural encounters. New York: A\&C Black.

Fransella, F. (ed.). (2003) International handbook of personal construct psychology. West Sussex, England: John Wiley \& Sons.

Graburn, N. H. (1995) The past in the present in Japan: nostalgia and neotraditionalism in contemporary Japanese domestic tourism. In Butler, R. W., \& Pearce, D. G. (eds.). Change in tourism: People, places, processes. London: Routledge, 47-70

Green, B. (2004) Personal construct psychology and content analysis. Personal Construct Theory \& Practice 1(3), 82-91

Guichard-Anguis, S., \& Moon, O. (eds.). (2008) Japanese tourism and travel culture. London: Routledge.

Iwashita, C. (2006) Media representation of the UK as a destination for Japanese tourists: Popular culture and tourism. Tourist studies 6(1), 59-77

Kato, K., \& Progano, R. N. (2017) Spiritual (walking) tourism as a foundation for sustainable destination development: Kumano-kodo pilgrimage, Wakayama, Japan. Tourism Management Perspectives 24, 243-251.

Kelly, G.A. (1955) The psychology of personal constructs, Vols. 1 and 2. New York: Norton.

Kodansha, International LTD. (2003) Keys to the Japanese Heart and Soul. Tokyo: Koudansha International Ltd.

Koren, L. (2008) Wabi-sabi for artists, designers, poets \& philosophers. California: Imperfect Publishing.

Krag, C. W. and Prebensen, N. K. (2016) Domestic Nature-Based Tourism in Japan: Spirituality, Novelty and Communing. In Joseph S. Chen (ed.). Advances in Hospitality and Leisure (Advances in Hospitality and Leisure, 
Volume 12). WA, UK: Emerald Group Publishing Limited, pp.51 - 64

Leximancer website (2016) http://info. leximancer.com/supported-languages

MacCannell, D. (1973) Staged authenticity: Arrangements of social space in tourist settings. The American Journal of Sociology, 79(3), 589-603

MacCannell, D. (1976) The tourist: $A$ new theory of the leisure class. New York: Schocken Books.

McCain, G., \& Ray, N. M. (2003) Legacy tourism: The search for personal meaning in heritage travel. Tourism Management 24(6), 713-717

Moeran, B. (1983) The language of Japanese tourism. Annals of Tourism Research 10(1), 93-108

Moore, A. (1985) Rosanzerusu is Los Angeles an anthropological inquiry of Japanese tourists. Annals of Tourism Research 12(4), 619-643

Moore, K. (2002) The discursive tourist. In G.M.S. Dann (ed.). The Tourist as Metaphor of the Social World. Wallingford, Oxon: CABI, 41-60

Neuschwanstein Homepage (2016). http://www.neuschwanstein.de/englisch/t ourist/index.htm

Nishimura, S., Waryszak, R., \& King, B. (2006). Guidebook use by Japanese tourists: a qualitative study of Australia inbound travellers. International Journal of Tourism Research 8(1), 13-26

Noe, F. P. (1999) Tourism Service Satisfaction. Champaign, IL: Sagamore.

Nyiri, P. (2006) Scenic Spots: Chinese Tourism, the State and Cultural Authority. Seattle, United States of America: University of Washington Press.

Pearce, P. L. (1988) The Ulysses Factor: Evaluating visitors in tourist settings. New York: Springer-Verlag.

Pearce, P. L. \& Wu, M.-Y. (2015) Soft Infrastructure at Tourism Sites: Identifying Key Issues for Asian Tourism from Case Studies. Tourism Recreation Research 40(1), 120-132

Pearce P. L. \& Wu, M.-Y. (2016) Tourists' evaluation of a romantic themed attraction: Expressive and instrumental issues. Journal of Travel Research 55(2), 220-232
Pearce, P. L., \& Wu, M.-Y. (eds). (2017) The World Meets Asian Tourists. Bingley: Emerald.

Pearce, P. L., Wu, M-Y., \& Osmond A. (2013) Puzzles in understanding Chinese tourist behaviour Towards a Triple- $C$ gaze. Tourism Recreation Research 38(2), 145-158

Prebensen, N. K., Vitters $\varnothing$, J., \& Dahl, T. I. (2013) Value co-creation significance of tourist resources. Annals of Tourism Research 42, 240-261

Putnam, R. D. (2001) Bowling alone: The collapse and revival of American community. New York: Simon and Schuster.

Rea, M. H. (2000) A furusato away from home. Annals of Tourism Research 27(3), 638660

Reynolds, R. (2013) Personal construct theory. In Wilson, T. (Ed). Theory in information behaviour research. Eiconics Ltd., pp. 68-82.

Rickly-Boyd, J. (2013) Existential authenticity: Place matters. Tourism Geographies 15(4), 680-686

Rojek, C. (1997) Indexing, dragging and the social construction of tourist sights. In C. Rojek and J. Urry (eds.). Touring Cultures: Transformations of Travel and Theory. London: Routledge, 52-74

Ryan, C. (1995) Researching tourist satisfaction: Issues, concepts, problems. London: Routledge.

Saipradist, A., \& Staiff, R. (2008) Crossing the cultural divide; Western visitors and interpretation at Ayutthaya world heritage site, Thailand. Journal of Heritage Tourism 2(3), 211-224

Seaton, P., \& Yamamura, T. (2015). Japanese popular culture and contents tourism Introduction. Japan forum 27(1), 1-11

Sheridan, G. (1999) Asian values Western dreams. St Leonards, NSW: Allen \& Unwin.

Siegenthaler, P. (2002) Hiroshima and Nagasaki in Japanese guidebooks. Annals of Tourism Research 29(4), 1111-1137

Steiner, C. J., \& Reisinger, Y. (2006) Understanding existential authenticity. Annals of Tourism Research 33(2), 299-318 
Surman, B. (2009) The search for the real thing: Japanese tourism to Britain. In Guichard-Anguis, S., \& Moon, O. (eds.). Japanese tourism and travel culture. London: Routledge, 193-202

Swan, J. E., \& L. J. Combs (1976) Product Performance and Consumer Satisfaction. Journal of Marketing 40, 25-33

TinySegmenter (2008) http://chasen.org/ taku/ software/TinySegmenter/

TripAdvisor (2016a) "TripAdvisor accounted '50 most popular tourist destinations for Japanese 2016 “. http://tg.tripadvisor. Jp /news/wp- content/uploads/2016/12/2016 1209_TripAdvisorPressRelease_]v2.pdf

TripAdvisor (2016b) Bucket List for World Castles. https://www.tripadvisor.jp/pages /Castle.html.
Urry, J. (1990) The tourist gaze: Leisure and travel in contemporary societies. London: Sage.

Wang, N. (1999) Rethinking authenticity in tourism experience. Annals of Tourism Research 26(2), 349-370

Watkins, L. J., \& Gnoth, J. (2011) Japanese tourism values: A means-end investigation. Journal of Travel Research 50(6), 654-668

Wu, M. Y., Wall, G., \& Pearce, P. L. (2014) Shopping experiences: international tourist in Beijing's silk market. Tourism Management 41, 96-106

Yagi, C., \& Pearce, P. L. (2017) Imagination, Anime and Japanese Tourists Abroad. In P. L. Pearce and M.-Y. Wu (eds.). The World Meets Asian Tourists. Bingley: Emerald, 267-286 